\title{
Use of seasonal climate information to predict coconut production in Sri Lanka
}

\author{
T. S. G. Peiris, ${ }^{\mathrm{a}}$ J. W. Hansen ${ }^{\mathrm{b}}$ and Lareef Zubair ${ }^{\mathrm{b} *}$ \\ ${ }^{a}$ Coconut Research Institute of Sri Lanka, Lunuwila, 01150, Sri Lanka \\ b International Research Institute for Climate and Society, Palisades, NY10964, USA
}

\begin{abstract}
Accurate forecasting of annual national coconut production (ANCP) is important for national agricultural planning and negotiating forward contracts. Climate and the long-term trends (attributed to 'technology') are major factors that determine ANCP. The effect of climate on ANCP of the following year was studied for the seven agro-ecological regions (AER's) in the principal coconut growing areas for the period 19502002. Climate was studied based on seasons aggregated by the monsoon calendar and by quarters that are consistent with the agricultural calendar. The use of quarterly seasons explained more of the variability of ANCP than the use of monsoon based seasons. January-March rainfall in all AER's and July-September rainfall in the wetter regions are positively correlated with the ANCP $(p<0.005)$. The technology effect was estimated using a log-linear trend model. The regression model integrates both climate and technology effects developed to predict ANCP with high fidelity $\left(R^{2}=0.94\right)$. The climate effect was estimated by regressing production data that had been de-trended to remove the technology effects with quarterly rainfall in the year prior to harvest. The most significant predictors were found to be the quarterly rainfall from the AER's in the coconut growing regions that are designated as wet and intermediate. Representative rainfall from each quarter was used in a regression model with corrections for the technology effect. The correlation between observed and predicted values of the ANCP was 0.83 $(p<0.001)$. The prediction of ANCP for 2003 and 2004 gave errors of only 6.5 and $7.0 \%$. The estimated value of ANCP for 2005 is 2715 million nuts, which is $12 \%$ higher than the mean. The lead time of the prediction extends to 15 months but it may be extended with the use of seasonal climate forecasts to 24 months. Copyright (C) 2007 Royal Meteorological Society
\end{abstract}

KEY WORDS climate; coconuts; yield prediction; Sri Lanka

Received 9 August 2005; Revised 3 February 2007; Accepted 3 February 2007

\section{Introduction}

Coconut is among the important tree crops of the humid tropical regions. The global annual production of coconut is around 52 billion nuts (Asian-Pacific Coconut Community, 2003). Sri Lanka ranks fourth in terms of the contribution to the world coconut production $(6 \%)$ and land extent under coconut (Peiris, 2004) after Indonesia, India and Philippines. In Sri Lanka, Coconut is grown as a plantation crop across seven of the 24 agro-ecological regions (AERs) (Mapa et al., 1999).

The annual national coconut production (ANCP) in Sri Lanka, between 1950 and 2003 varied from 1948 million nuts in 1973 to 3039 million nuts in 1986, with a mean of 2427 (Peiris, 2004). Coconut contributed 1.3\% of Sri Lanka's GNP in 2002 (Central Bank, 2003). Coconut provides about $22 \%$ of the daily calories of the Sri Lankan population and is second only to rice in providing nutrition. Sri Lanka's annual per capita consumption of coconut of 95-100 nuts is the highest in

\footnotetext{
* Correspondence to: Lareef Zubair, International Research Institute for Climate and Society, The Earth Institute of Columbia University, Palisades, New York, NY 10964-8000, USA. E-mail: lareef@iri.columbia.
} edu the world (Ministry of Plantation Industries, 2003). The nuts remaining after local consumption are used for fresh nut export and to manufacture products such as desiccated coconut, coconut oil, copra, coconut milk powder and coconut milk cream.

The coconut is a perennial crop and it has a prolonged reproductive phase of 44 months from the initiation of the inflorescence primordium to full maturity of the nuts. The inflorescence is enclosed in a spathe and includes both male and female flowers. Inflorescences are produced by the coconut palm at the rate of nearly one a month. The pre-fertilization phase from the initiation of the flower primordium to emergence accounts for 32 months. The fertilization and post-fertilization phases (the development of female flowers into nuts) takes 12 months during which period the spathe is open (Menon and Pandalai, 1958). Weather affects all stages of the long development cycle extending to 44 months and thus there is likely to be extended predictability based on climate variability.

For a given farm, when other external factors are non-limiting; rainfall, temperature and relative humidity during February, June, July, September and December in the year prior to the harvest are the major factors that 
influence the yield (Peiris and Thattil, 1998). Locationspecific predictive models to predict annual coconut yield have been developed using climatic variables alone (e.g. Nambiar, 1969; Reynolds, 1979; Mathew et al., 1991; Peiris et al., 1995; Peiris and Thattil, 1998). Rainfall is the principal climatic variable that affects nut production (Peiris and Thattil, 1998). The influence on ANCP is primarily from the rainfall in the year preceding the harvest rather than the coincident year. Because of the climate variability across AER's, it is necessary to consider rainfall in each individual AER and season rather than annual total Sri Lanka rainfall in devising a prediction scheme (Abeywardena, 1968; Peiris et al., 2000; Peiris, 2004).

The major factors that determine the ANCP are (1) climatic variations in the principal coconut growing regions, (2) use of fertilizer and other recommended agronomic practices (3) intensity of pest and disease control and (4) area of bearing coconut (Peiris and Thattil, 1998). Annual data for the last three variables are not available at the national or regional scale. However, the combined influence of fertilizer use, control of pest and diseases and the use of new technology on ANCP has to be considered in addition to the influence of climate.

Advance knowledge of coconut production at national and regional scales is useful for planning within the industry, for allocation of nuts among various sectors and for agreements of forward contracts with foreign purchasers. The official ANCP prediction for Sri Lanka is being provided by the first author and colleagues at the Coconut Research Institute using an autoregressive integrated moving average (ARIMA) model (Box and Jenkins, 1981). The correlation coefficient between observed and modeled ANCP was $R=0.73$.

ARIMA models are the most general class of models for forecasting time series data where there is a significant serial correlation. The autocorrelations of ANCP years were significant $(p<0.05)$ with a lag of 1,3 and 4 years and this relationship may be exploited to predict the yield in the subsequent year with some skill (Peiris, 2004). This extended relationship could be due to the long (44 months) development cycle of a coconut bunch. Unlike with use of regression models, this method does not need any external variables as predictor variables. The main disadvantage of this model is that it does not explicitly account for the variability of climate.

In this paper, we characterize the impact of seasonal climate variability of ANCP and develop a national coconut production forecast model that incorporates key climatic variables in addition to a model that captures the influence of 'technology effect'.

\section{Data and methods}

\subsection{Agro-ecological regions}

AERs are demarcated based on climate, soils and topography (Panabokke, 1996). Sri Lanka is divided among wet, intermediate and dry zones based on annual rainfall and as low, mid and up country based on elevation. The AERs use these two variables as primary classifiers with the first letter denoting $\mathrm{W}$, I or D to indicate the climatic zone and the second letter (L, M, U) to indicate the elevation (Figure 1). Each of these regions is then further classified based on soils and the seasonal distribution of rainfall.

\section{2. $\mathrm{ANCP}$}

The ANCP from 1950 to 2003 was obtained from the Coconut Development Authority of Sri Lanka (Ministry of Plantation Industries, 2003). The temporal variability of the ANCP is shown in Figure 2. Along with the interannual variability, this figure shows significant trends such as a declining trend between 1963 and 1977, followed by an increasing trend to the present.

Coconut is cultivated over approximately 394836 ha in Sri Lanka. A large fraction of the coconut plantations (77\%) are located in seven AERs (Figure 1). The approximate distribution of planted extent by AER is estimated as IL1-20\%, IL3 - 13.8\%, DL3 - 11.7\%, DL5 - 5.3\%, WL4-11.4\%, WL3 - 10.9\% and WL2 - 3.9\%. However, annual nut production is available only by national level, but not by AER level or administrative district level in Sri Lanka. Given the longevity of the coconut plantation, there is limited year-to-year fluctuation of the area under cultivation and the distribution of coconut production among the different AER's.

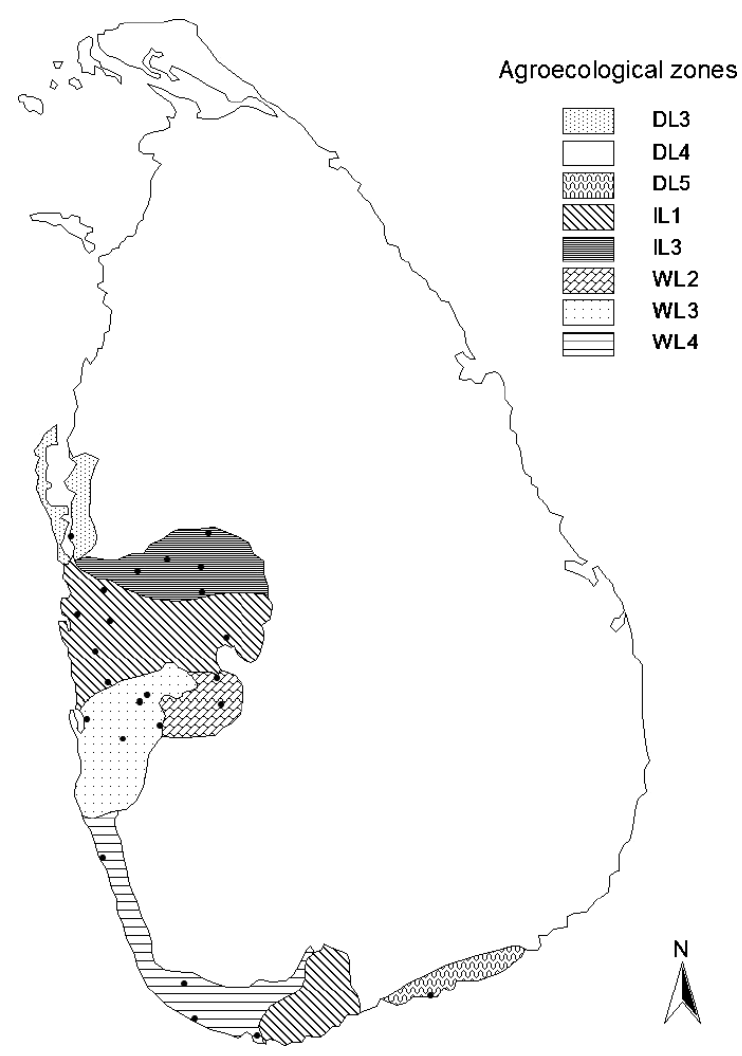

Figure 1. The agro-ecological regions (AER's) that include significant coconut cultivation are shown in the map along with the rainfall stations that were used. 


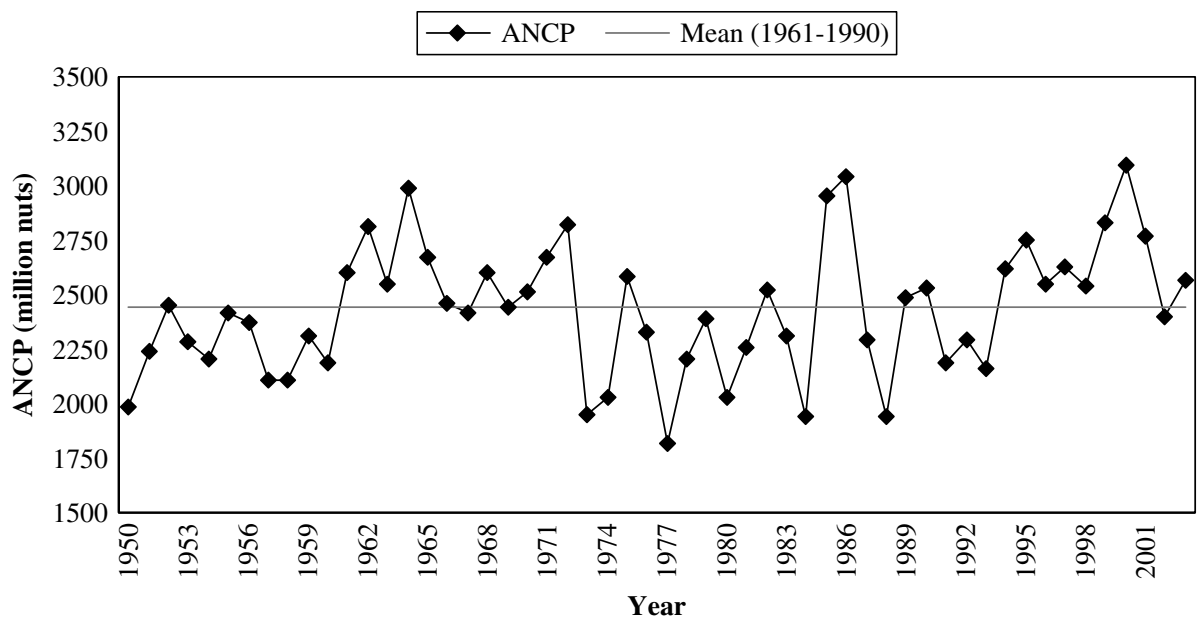

Figure 2. The annual national coconut production (ANCP) in Sri Lanka. The horizontal line indicates the mean of the base period from 1961 to 1990.

Table I. Rates of annual increase for each climate variable (significant at least $p<0.05$ ) in principal coconut-growing regions.

\begin{tabular}{|c|c|c|c|c|c|c|c|c|c|}
\hline \multirow[t]{2}{*}{ AER } & \multicolumn{3}{|c|}{ Rainfall (mm) } & \multicolumn{3}{|c|}{$\mathrm{T}_{\mathrm{MAX}}\left({ }^{\circ} \mathrm{C}\right)$} & \multicolumn{3}{|c|}{$\mathrm{T}_{\mathrm{MIN}}\left({ }^{\circ} \mathrm{C}\right)$} \\
\hline & mean & SD & Trend & mean & SD & trend & mean & SD & trend \\
\hline $\mathrm{IL}_{1}$ & 1662 & 279 & $-3.85^{*}$ & 31.5 & 0.6 & $0.011^{*}$ & 23.1 & 0.5 & $\mathrm{~ns}$ \\
\hline $\mathrm{IL}_{3}$ & 1380 & 248 & $-5.16^{*}$ & $\mathrm{n} / \mathrm{a}$ & $\mathrm{n} / \mathrm{a}$ & - & $\mathrm{n} / \mathrm{a}$ & $\mathrm{n} / \mathrm{a}$ & - \\
\hline $\mathrm{WL}_{3}$ & 2224 & 438 & $-6.76^{*}$ & 33.3 & 0.6 & $0.019^{*}$ & 23.7 & 0.3 & ns \\
\hline $\mathrm{WL}_{4}$ & 2435 & 451 & $-7.66^{*}$ & 29.3 & 0.3 & $0.018^{*}$ & 24.2 & 0.4 & $0.013^{*}$ \\
\hline $\mathrm{WL}_{2}$ & 2287 & 555 & $-7.24^{*}$ & $\mathrm{n} / \mathrm{a}$ & $\mathrm{n} / \mathrm{a}$ & - & $\mathrm{n} / \mathrm{a}$ & $\mathrm{n} / \mathrm{a}$ & - \\
\hline $\mathrm{DL}_{3}$ & 1193 & 307 & ns & 31.6 & 0.5 & $0.027^{*}$ & 24.0 & 0.3 & $0.021^{*}$ \\
\hline $\mathrm{DL}_{5}$ & 1033 & 264 & ns & 30.3 & 0.3 & $0.019^{*}$ & 24.2 & 0.2 & $0.013^{*}$ \\
\hline
\end{tabular}

(n/a, data not available; $*$, significant at least $p=0.05$; ns-not significant at $p=0.05$ ).

\subsection{Climate data}

Daily rainfall data (1948-2003) from the seven principal coconut growing AERs (Table I) were acquired for the stations within AER as shown in Figure 1. Daily data were quality controlled and missing data were estimated using a single moving average/single exponential smoothing technique (Box and Jenkins, 1981). Mean annual daily maximum air temperature $\left(\mathrm{T}_{\mathrm{MAX}}\right)$ and minimum air temperature $\left(\mathrm{T}_{\mathrm{MIN}}\right)$ were obtained for each AER except IL3 and $\mathrm{WL}_{2}$. Temperature data were not available in those two AERs.

\subsection{Seasons}

Sri Lanka receives rainfall throughout the year, with a bimodal seasonal distribution. The seasonal peaks vary by region with the peak of the main rainfall season occurring in October, November or December and the subsidiary peak occurring in April, May or June. In the southwest hill slopes of the island there is heavy rainfall from July to September as well, but in the rest of the island this period along with January to March may be prone to droughts. On account of the regional and seasonal variability in rainfall, the demarcation of seasons is not clear-cut. Meteorologists have classified the annual cycle into four seasons consistent with the seasons defined by the Indian Meteorological Department (Bamford, 1922):

- Northeast monsoon (NEM) from December to February,

- First inter-monsoon (FIM) from March to April,

- Southwest monsoon (SWM) from May to September

- Second inter-monsoon (SIM) from October to November.

However, this is not consistent with the agricultural seasons with respect to traditional rice cultivation and harvesting which lasts from October to March (Maha) and April to September (Yala). Recent work (Zubair, 2002, 2003) has shown that Sri Lanka's climate, stream flow and rice production show greater predictability based on El Niño-Southern Oscillation (ENSO) when the quarters are chosen to be consistent with the early and late halves of the agricultural seasons. These predictions were statistical based on ENSO indices derived from the sea surface temperatures (SST) in the Pacific Ocean either at the start of the season or during the season in question. The use of Indian Ocean SST in the predictions improves the skill of predictions (Zubair et al., 2003). 
- Early Yala: April-June (AMJ),

- Late Yala: July-September (JAS),

- Early Maha: October-December (OND) and

- Late Maha: January-March (JFM).

The principal large-scale climate modes that influence the rainfall over Sri Lanka are the ENSO (Zubair and Ropelewski, 2006) and the Indian Ocean Dipole (Zubair et al., 2003). El Niño typically leads to wetter anomalies (from climatology) during October to December and to drier anomalies during January to March and July to August on average. La Niña typically leads to drier than normal conditions during the months October to December and to wetter than normal conditions during July and August. The positive Indian Ocean Dipole (warmer than normal SST in the Arabian Sea and cooler than normal SST near Sumatra) co-occurs frequently but not always with El Niño. With a positive Indian Ocean Dipole, the rainfall from September to December is enhanced and with the negative dipole, the September to December rainfall is diminished. All of these relationships are more consistent with the quarterly seasons chosen as the first and second half of each agricultural season rather than the monsoon wind based seasons.

As a result greater predictability is obtained with the quarterly seasons. On the other hand, the NEM season, for example, combines months with increased rainfall (December) and decreased rainfall (January to February) with ENSO. Indeed, the SWM monsoon period from May to September may mask important seasonal variability. A correlation of May to June rainfall with July to September rainfall for all of Sri Lanka between 1950 and 2000 shows a negative correlation of -0.15 which while not statistically significant still suggests that the rainfall in the early part of the season is, if at all, anti-correlated with that in the later part of the season.

A further advantage in the use of quarterly seasons is that seasonal climate predictions are provided for quarters by forecasting centers (Goddard et al., 2004) and these predictions shall be more easily incorporated into the ANCP prediction.

We compare the predictability of ANCP using rainfall obtained with both classifications of seasons in this paper.

\subsection{Prediction of technology effect}

In addition to the influence of climate effect, the use of fertilizer, control of pest and diseases and the use of improved management practices affect the ANCP. As there are no data to estimate the latter factors individually, we may attribute the long-term changes to the combination of these and related factors, which are referred to as the 'technology effect'. There is no theoretical basis for identification one functional form to another for technology effect (Hansen et al., 1998). Therefore, a suitable functional form may be chosen which best captures the temporal variation of ANCP.

\subsection{Integration of climate and technology effects}

The historical yield series was considered to be comprised of multi-year trends that reflect change due to technology and inter-annual anomalies from this trend was attributed to seasonal changes in climate. The final form of the model should consider the combination of these influences. Both additive,

$$
\begin{aligned}
& \text { Yield }=\text { constant }+ \text { technology effect }+ \text { climate } \\
& \text { variability effect }+ \text { noise effect, }
\end{aligned}
$$

and multiplicative functional forms,

$$
\begin{aligned}
& \text { Yield }=\text { constant }+ \text { technology effect } \times \text { climate } \\
& \text { variability effect } \times \text { noise effect, }
\end{aligned}
$$

(Chatfield, 2000) for the decomposition of the time series were tested.

A multiplicative model assumes that standard deviation changes proportionally, or equivalently, coefficient of variation is constant, with changing central tendency associated with a trend. This would be the case if a production trend were due entirely to the expansion of an area under stationary climate and constant production technology. In a multiplicative model, year-to-year variations can be interpreted as a percent deviation from the trend. The additive model, on the other hand, treats departures from the trend in central tendency as differences, and assumes that variability about the trend is constant. An additive model would be consistent, for example, with changing technology that increases yields by an annual increment independently of weather.

\subsection{Statistical analyses}

The correlation analysis was first carried out between ANCP and total rainfall of each seasonal component (NEM, FIM, SWM and SIM for monsoon rainfall and JFM, AMJ, JAS and OND for quarterly rainfall) separately for each AER to identify the significant rainfall variables.

Candidate models to predict ANCP were considered based on the two formulations of the yield (Equations 1 and 2) and the two formulations of seasons. For each candidate the set of rainfall predictors that were significantly influential were selected by backward elimination stepwise regression technique that starts with all rainfall variables (Draper and Smith, 1966). This method handles the co-linearity problem better than other stepwise techniques. The most suitable model was selected based on the magnitude of the adjusted $R^{2}$ value (coefficient of determination) and the range of errors of the predicted ANCP.

The adjusted $R^{2}$ statistic is calculated as Adj. $R^{2}=$ $1-\left[\left((\mathrm{n}-1)\left(1-R^{2}\right)\right) /(\mathrm{n}-p)\right]$ where $\mathrm{n}$ is the number of observations used in fitting the model with intercept, $p$ is the number of parameters and $R^{2}$ is the ratio between 
model sums of squares and total sums of squares (Draper and Smith, 1966).

Once the best seasonal type model was identified, the effect of climate was examined after removing the trend attributed to the 'technology effect' from the original data under two model formulations. Having identified the better model out of the two models, residuals of the selected model were evaluated for independence using Durbin-Watson (DW) statistics, which is a common procedure to test for serial correlations in regression models (Draper and Smith, 1966). The model that best fitted the ANCP for 1950-2002 was then used to predict ANCP for 2003 and 2004.

\section{Results and discussion}

\subsection{Trend in rainfall and temperature}

The spatially aggregated annual mean values of the three climate variables (rainfall, maximum air temperature and minimum air temperature) of the seven AERs in principal coconut growing areas and their annual rate of increases are shown in Table I. The rate of increase was obtained by fitting a simple linear trend model $(y=a+b t)$ for each data series separately. All the AERs except DL3 and DL5 exhibited a significant decreasing trend in annual rainfall $(p<0.05)$. All regions showed a significant increasing trend for $\mathrm{T}_{\mathrm{MAX}}$ and a significant increasing trend for $\mathrm{T}_{\mathrm{MIN}}$ was found only in WL4, DL3 and DL5. The rate of increase was greater for $T_{\text {MAX }}$ than for $T_{M I N}$ with the difference in the two trends being significant in WL4, DL3 and DL5.

\subsection{Use of monsoon seasons rainfall to predict ANCP}

The distribution of monsoon seasonal rainfall is different among AERs (Figure 3). Rainfall is lowest in the NEM except in DL5. Rainfall is greatest during the SWM in wet regions and during the SIM in other regions. Analysis of ANCP and monsoon seasonal rainfall within each AER showed significant correlations with rainfall logged 1 year prior to harvest (Table II). No significant correlation was found between yield and monsoon seasonal rainfall of the harvesting year. This confirms the importance of rainfall distribution in the preceding year for the ANCP. In fact many authors (Gangolly, 1953; Abeywardena, 1955; Nambiar, 1969) claim that during the 44 months development cycle the effect of climate on nut production is more significant after the spathe opens because the coconut bunches are fully exposed to climate during this period

NEM rainfall in all regions and SWM rainfall in wet regions are positively correlated at significant levels with ANCP (Table II). The influence of rainfall on national coconut production in the coconut growing areas during NEM and SWM is stronger than the influence of rainfall during the intervening periods. The correlations between ANCP and SIM rainfall are negative but not significant. This is probably because rainfall in October and November is generally much higher than the crops'

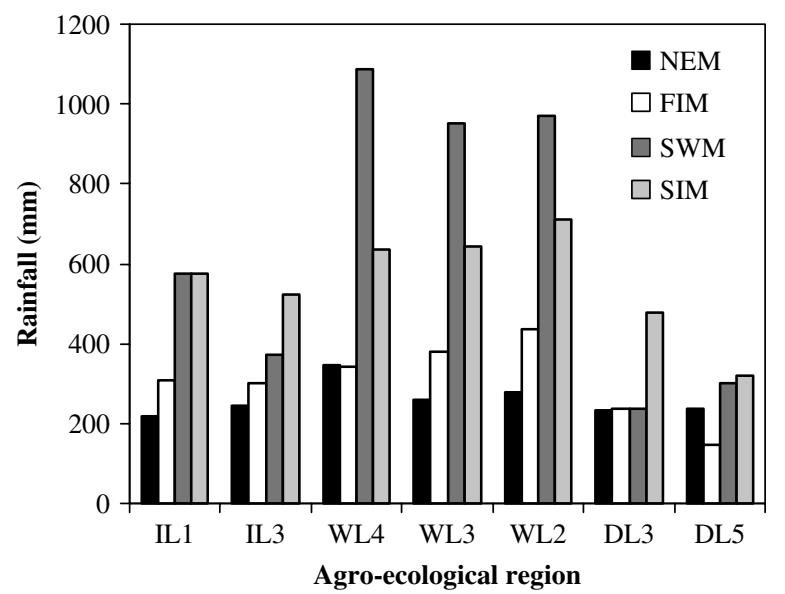

Figure 3. Distribution of rainfall by monsoon seasons in the seven agro-ecological regions in the principal coconut growing areas.

Table II. Correlation between ANCP and the monsoon seasonal rainfall with rainfall lagging $\mathrm{ANCP}$ by at least a year.

\begin{tabular}{llccc}
\hline AER & NEM & FIM & SWM & SIM \\
\hline IL1 & $0.445^{* * *}$ & $\mathrm{~ns}$ & $\mathrm{~ns}$ & $\mathrm{~ns}$ \\
IL3 & $0.381^{* *}$ & $\mathrm{~ns}$ & $\mathrm{~ns}$ & $\mathrm{~ns}$ \\
WL4 & $0.327^{*}$ & $\mathrm{~ns}$ & $0.299^{*}$ & $\mathrm{~ns}$ \\
WL3 & $0.418^{* *}$ & $0.292^{*}$ & $0.296^{*}$ & $\mathrm{~ns}$ \\
WL2 & $0.355^{* *}$ & $\mathrm{~ns}$ & $0.443^{* *}$ & $\mathrm{~ns}$ \\
DL3 & $0.385^{* *}$ & $0.295^{*}$ & $\mathrm{Ns}$ & $\mathrm{ns}$ \\
DL5 & $0.303^{*}$ & $\mathrm{Ns}$ & $\mathrm{ns}$ & $\mathrm{ns}$ \\
& & & & \\
\hline
\end{tabular}

(* $p<0.05$; ${ }^{* *} p<0.01$; ${ }^{* * *} p<0.001$; ns, not significant).

maximum water demand of $5 \mathrm{~mm} \mathrm{~d}^{-1}$ (300 $\mathrm{mm}$ for the 2 months). Rainfall above this critical value does not benefit the tree.

The NEM rainfall and SWM rainfall shows high correlation $(p<0.001)$ among the seven AERs. However, these cross-region correlations were not significant for the FIM and SIM seasons. The correlations may be weaker as these seasons are only 2 months long. ANCP was not significantly correlated with monsoon season temperature (maximum and minimum) of AER's. Note, that the significant association between coconut production and temperature reported previously (Peiris and Thattil, 1998) was for a specific plantation and for only the months of June, July and December. There were no significant associations across the seasons in use.

The model that best predicts ANCP based on monsoon season rainfall is

$$
\begin{aligned}
& \mathrm{Y}_{\mathrm{t}}=1751+1.26 \mathrm{RF}^{(\mathrm{WL} 3)} \mathrm{NEM,t-1} \\
& +0.436 \mathrm{RF}^{(\mathrm{WL} 2)} \mathrm{SWM}, \mathrm{t}-1
\end{aligned}
$$

(Adjusted $R^{2}=0.30, p<0.002$ ). The predictors are NEM rainfall in WL3 and SWM rainfall in WL2. Equation 3 explains $30 \%$ of the variability of ANCP. 


\subsection{Use of quarterly seasons to predict ANCP}

Rainfall is lowest during January-March except in DL3, IL3 and DL5 (Figure 4). It exceeds $400 \mathrm{~mm}$ during October-December in all AERs.

ANCP is positively correlated $(p<0.05)$ with rainfall during January-March in all seven AERs and July-September in all AERs except the two driest (Table III). This is probably because water demand for crop during these periods would not be met due to longer dry spells leading to closure of the stomata, and a slowing down of photosynthesis resulting in low nut production (Peiris and Thattil, 1998). Thus regular showers during the first 3 months in all coconut-growing areas would increase the ANCP in the following year. The April-June rainfall in the AERs that are in the WL2 and WL4 were also positively correlated with ANCP.

The number of significant correlations and their magnitudes are only modestly greater for quarterly rainfall (Table III) rather than for rainfall grouped by monsoon season (Table II).

The best model and parameters to predict ANCP from quarterly rainfall is

$$
\begin{gathered}
\mathrm{Y}_{\mathrm{t}}=1776+0.875 \mathrm{RF}^{(\mathrm{DL} 3)}{ }_{\mathrm{JFM}, \mathrm{t}-1}+0.572 \\
\mathrm{RF}^{(\mathrm{WL} 2)}{ }_{\mathrm{JAS}, \mathrm{t}-1}+0.297 \mathrm{RF}^{(\mathrm{WL} 2)}{ }_{\text {AMJ }, \mathrm{t}-1}
\end{gathered}
$$

(Adjusted $R^{2}=0.44, p<0.0001$ ).

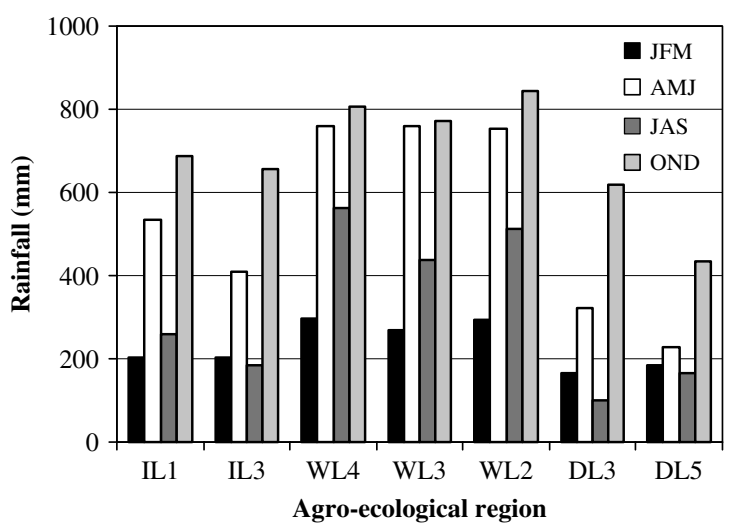

Figure 4. Distribution of rainfall by quarterly seasons in the seven agro-ecological regions that span the principal coconut growing areas.

Table III. Correlation between ANCP and quarterly rainfall in the year prior to harvest.

\begin{tabular}{llccc}
\hline \multirow{2}{*}{ AER } & \multicolumn{4}{c}{ Three month seasonal period } \\
\cline { 2 - 5 } & JFM & AMJ & JAS & OND \\
\hline IL1 & $0.435^{* * *}$ & $\mathrm{~ns}$ & $0.282^{*}$ & $\mathrm{~ns}$ \\
IL3 & $0.391^{* *}$ & $\mathrm{~ns}$ & $0.353^{* *}$ & $\mathrm{~ns}$ \\
WL4 & $0.334^{* *}$ & $0.288^{*}$ & $0.288^{*}$ & $\mathrm{~ns}$ \\
WL3 & $0.411^{* *}$ & $\mathrm{~ns}$ & $0.284^{*}$ & $\mathrm{~ns}$ \\
WL2 & $0.359^{* *}$ & $0.386^{* *}$ & $0.483^{* * *}$ & $\mathrm{~ns}$ \\
DL3 & $0.452^{* * *}$ & $\mathrm{~ns}$ & $\mathrm{~ns}$ & $\mathrm{~ns}$ \\
DL5 & $0.357^{* *}$ & $\mathrm{~ns}$ & $\mathrm{~ns}$ & $\mathrm{~ns}$ \\
& & & & \\
\hline
\end{tabular}

( ${ }^{*} p<0.05 ;{ }^{* *} p<0.01 ;{ }^{* * *} p<0.001$; ns, not significant).
All the predictor variables were significant at $p=0.05$ and they were not significantly correlated with each other. There was no significant correlation between ANCP and quarterly seasonal temperatures.

The substantial increase of $R^{2}$ from 30 to $44 \%$ associated with Equation (4) compared with Equation (3) suggests that quarterly rainfall is a better predictor of ANCP than monsoon season rainfall. The variance explained is also greater with the use of quarterly seasons. Thus it can be concluded that the use of quarterly seasonal rainfall is statistically more skillful than the use of monsoon seasonal rainfall for the use of prediction of ANCP. Further, the quarterly rainfall is a better representation for the distribution of rainfall within a year than monsoon rainfall.

Yet, even with the improvement, the variance explained is still less than $50 \%$ and the residuals from both models (Equation 3 and 4) show significant first-order autocorrelation $(p<0.005)$. To address these issues we have attempted to factor in the technology effect below.

\subsection{Identification of the technology effect}

Spectral analysis showed that ANCP did not have cyclical patterns. The technology effect could be assumed to be modelled by a simple time-dependant model which is either linear: $\mathrm{Y}_{\mathrm{t}}=\mathrm{a}+$ bt or log-linear: $\mathrm{Y}_{\mathrm{t}}=\mathrm{e}^{(\alpha+\beta \mathrm{t})}$. The linear model was not significant (Adjusted $R^{2}=0.06$ ). The log-linear model was significant $(p<0.005)$ and explained $17 \%$ of variability of the ANCP. Therefore, the log-linear model was selected as a suitable time dependant model to remove the trend due to the technology effect.

\subsection{Climate effect}

The 'climate effect' was found to be modeled better when the rainfall indices were chosen as the quarterly rainfall for the different AER's for the ANCP time series. To improve on the representation of the climate effect after accounting for the 'technology effect', we revisited this analysis with detrended ANCP data. The best model for the 'climate effect' for the detrended ANCP data includes five variables of quarterly rainfall chosen from the seven AERs as predictors (Table IV). These five variables explain the climate effect of the detrended series with a cumulative $R^{2}$ of 0.77 which is highly significant. Note that there is a significant correlation between January-March rainfall in WL3 and WL4 and April-June rainfall in WL2 and IL3. However, including their interaction terms did not improve the model's $R^{2}$ significantly.

\subsection{Additive vs. multiplicative model}

In order to choose between additive and multiplicative models, separate regression models were developed to explain the variability of the detrended data under the two forms of models using backward elimination stepwise regression method (Draper and Smith, 1966). The statistical indicators that were used to compare the two 
Table IV. Summary of the significant parameters for the detrended data under the additive model. RF indicates rainfall, the superscript indicates the AER and the subscript the quarter. A subscript of $(t-1)$ refers to the year prior to the harvest.

\begin{tabular}{|c|c|c|c|c|c|}
\hline Predictor & Coefficient & SE & Pr. $>$ F & Partial $R^{2}$ & Cumulative $R^{2}$ \\
\hline Intercept & -823.3 & 122.5 & $<0.0001$ & - & - \\
\hline $\mathrm{RF}^{(\mathrm{WL} 3)_{\mathrm{JFM}, \mathrm{t}-1}}$ & 0.674 & 0.286 & 0.023 & 0.38 & 0.38 \\
\hline $\mathrm{RF}^{(\mathrm{WL} 2)}{ }_{\mathrm{AMJ}, \mathrm{t}-1}$ & 0.784 & 0.127 & $<0.0001$ & 0.20 & 0.58 \\
\hline $\mathrm{RF}^{(\mathrm{WL} 4)} \mathrm{JAS}, \mathrm{t}-1$ & 0.570 & 0.119 & $<0.0001$ & 0.12 & 0.70 \\
\hline $\mathrm{RF}^{(\mathrm{WL} 4)}{ }_{\mathrm{JFM}, \mathrm{t}-1}$ & 0.748 & 0.335 & 0.030 & 0.04 & 0.74 \\
\hline $\mathrm{RF}^{(\mathrm{IL} 3)}$ AMJ,t-1 & -0.649 & 0.244 & 0.010 & 0.03 & 0.77 \\
\hline
\end{tabular}

(Adj. $\left.R^{2}=0.76, p<0.0001\right)$.

models are shown in Table V. The Adjusted $R^{2}$ is higher for the additive model than for the multiplicative model (Table V). Further, the DW statistic confirms that the residual of the additive model is white noise. Thus the additive model represents the detrended data better than the multiplicative model.

\subsection{Final ANCP prediction model}

The final model which combines technology and climate effects is of the form,

$$
A N C P_{t}=\mu+\exp (\alpha+\beta t)+\sum_{i=1}^{5} \theta_{i}^{*} R F_{i, t-1}
$$

and provides a highly significant fit to the data $(p<$ $0.001) . \mu$ is the intercept, $\theta_{i}(i=1,2,3,4$ and 5) are the parameters of the predictor variable $\mathrm{RF}_{\mathrm{i}, \mathrm{t}-1}$ and $\alpha$ and $\beta$ are the parameters of the log-linear model. Equation 5 accounted for $94 \%$ of the inter-annual variability of
ANCP (Figure 5) and the correlation between observed and modeled values was 0.83 which improves on the correlation $(R=0.73)$ for the ARIMA model. The lead time of the model is up to 15 months. Thus, ANCP realized at the end of the next year can be predicted by October based on the quarterly rainfall of the first three quarters of the current year.

The error between the model and the production; ranges between -10 to $+10 \%$, with the exception of a $25 \%$ under-prediction in 1988. Forward predictions of the ANCP using the model for 2003 and 2004 led to errors of 6.5 and $7.0 \%$ respectively. The model predicts 2715 million nuts for 2005 .

\section{Conclusions}

A regression model that incorporates quarterly rainfall for the year prior to harvest along with a scheme that accounts for the 'technology effect' explains a substantial

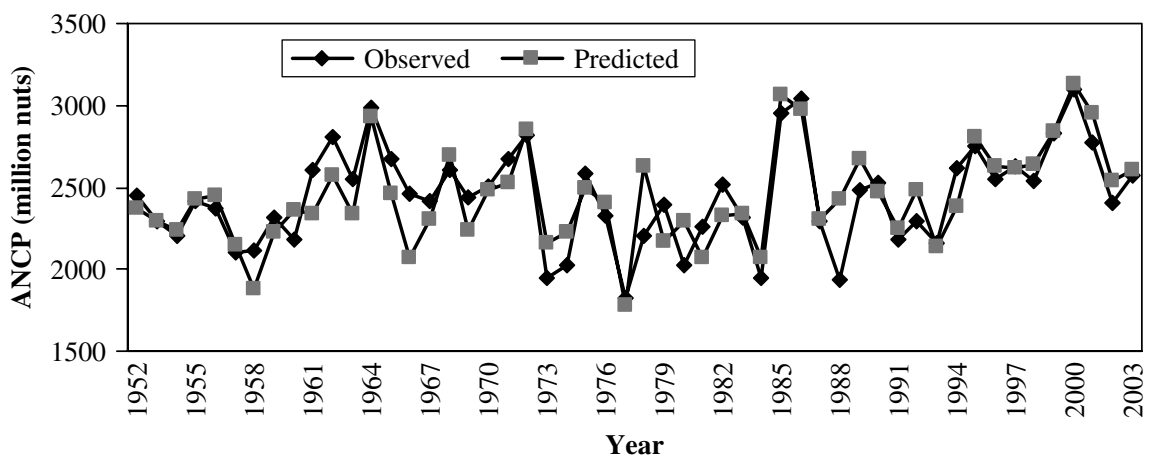

Figure 5. The observed and predicted annual coconut production based on Equation 5.

Table V. Comparison of statistical indicators between two models to incorporate both climate and technology in prediction (additive $v s$ multiplication).

\begin{tabular}{lccccc}
\hline Model & \multicolumn{3}{c}{ Statistical Indicator } \\
\cline { 2 - 6 } & $\begin{array}{c}\text { Significance } \\
\text { level }\end{array}$ & $\begin{array}{c}\text { Number of } \\
\text { significan } \\
\text { variables }\end{array}$ & $\begin{array}{c}\text { Adj. } \\
\mathrm{R}^{2}\end{array}$ & $\begin{array}{c}\mathrm{DW} \\
\text { statistic }\end{array}$ & $\begin{array}{c}\text { Residual } \\
\text { autocorrelation } \\
\text { of lag } 1\end{array}$ \\
\hline Additive & $p<0.0001$ & 5 & 0.76 & 1.768 & $0.101(p>0.005)$ \\
Multiplicative & $p<0.0001$ & 3 & 0.67 & 1.444 & $0.305(p<0.005)$ \\
\hline
\end{tabular}


portion $(94 \%)$ of the inter-annual variability of coconut production in Sri Lanka. The correlation between the observed and simulated models was $0.83(p<0.001)$. The prediction of ANCP for 2003 and 2004 based on this model gave predictions that were only $6.5 \%$ and $7.0 \%$ away from the observed. The use of rainfall seasons which are based on quarters consistent with the agricultural seasons improves markedly upon the use of monsoon seasons in the skill of ANCP predictions.

ANCP is sensitive to rainfall during January-March and to a lesser degree during July-September in the principal coconut growing regions. In coconut growing areas the periods during January to March and July to August generally have more dry spells which has more significant impact for coconut yield. ANCP is not sensitive to the rainfall during the wettest quarter from October to December. ANCP was not significantly sensitive to regional temperature trends. The use of quarterly rainfall is more skillful than the use of monsoon rainfall to predict ANCP and is of greater utility.

The annual yield can be predicted 15 months in advance from observed rainfall. The prediction lead-time of the seasonal rainfall based models can potentially be extended from 15 months to about 24 months by the use of available seasonal climate forecasts (Hansen, 2002).

\section{Acknowledgements}

This project was supported by the assessment of impacts of and adaptation to climate change program managed by the International START Secretariat and sponsored by the United Nations Environment Program and the Third World Academy of Sciences. The support of the Director and staff of the Biometry Division of Coconut Research Institute (CRI) and the International Research Institute for Climate and Society is gratefully acknowledged. Data were obtained from the Climate database of the Biometry Division of the CRI and the Sri Lanka Department of Meteorology. The assistance of Neil Ward, Janaka Ratnasiri, Senaka Basnayake, Sanathanie Ranasinghe, Neil Fernando, Champa Piyasiri, Sagara Chandrakumara, Manjula Siriwardhene, Rasika Perera, Zeenas Yahiya, and Udula Abeysinghe is gratefully acknowledged. This paper is funded in part by a grant/cooperative agreement from the National Oceanic and Atmospheric Administration, NA050AR4311004. The views expressed herein are those of the authors.

\section{References}

Abeywardena V. 1968. Forecasting coconut crops using rainfall data - a preliminary study. Ceylon Coconut Plantation Review 19: $161-176$.
Abeywardena V. 1955. Rainfall and Crops. Ceylon Coconut Quarterly 6: $17-21$.

Asian-Pacific Coconut Community. 2003. Coconut Statistical Yearbook. Asian and Pacific Coconut Community: Jakarta.

Bamford AJ. 1922. Ceylon rainfall. Quarterly Journal of the Royal Meteorological Society LXVIII(202): 206-207.

Box GEP, Jenkins GM. 1981. Time Series Analysis: Forecasting and Control. Holden-Day: San Francisco, CA.

Central Bank. 2003. Annual Report of the Central Bank of Sri Lanka. Central Bank: Colombo.

Chatfield C. 2000. The Analysis of Time Series: An Introduction, 6th edn. CRC Press: Boca Raton, FL.

Draper NR, Smith R. 1966. Applied Regression. John Wiley and Sons: New York.

Gangolly SR. 1953. A resume of investigations on shedding of buttons in the coconut. Indian Coconut Journal 6: 60-66.

Goddard L, Mason SE, Zebiak CF, Ropelewski RB, Cane MA. 2004. Current approaches to seasonal to inter-annual climate predictions. International Journal of Climatology 21(9): 1111-1152.

Hansen JW. 2002. Realizing the potential benefits of climate prediction to agriculture: issues, approaches, challenges. Agricultural Systems 74: $309-330$.

Hansen JW, Hodges AW, Jones JW. 1998. ENSO Influences on Agriculture in the Southeastern United States. Journal of Climate 11: 404-411.

Mapa RB, Somasiri S, Nagarajah S. 1999. Soils of the Wet zone of Sri Lanka. Soil Science Society of Sri Lanka: Colombo.

Mathew CH, Vijaya Kumar K, Nambiar PTN, Amaranath CH. 1991. Forecasting of annual yield of coconuts based on biometrical characters. Coconut Research and Development 7(1): 24-34.

Menon KEV, Pandalai KM. 1958. The Coconut Palm - A Monograph. Indian Central Coconut Committee: Ernakulam.

Ministry of Plantation Industries. 2003. Plantation Sector Statistical Pocket Book. Ministry of Plantation Industries: Colombo 2.

Nambiar MC. 1969. Preliminary observations on growth of and the likely effect of seasons on nut development in coconut. Indian Journal of Agricultural Sciences 39: 455-461.

Panabokke CR. 1996. Soils and Agro-ecological Environments of Sri Lanka. Natural Resource Energy and Science Authority of Sri Lanka: Colombo.

Peiris TSG. 2004. Forecasting coconut production: issues, approaches, challenges. In Proceedings of the International Conference of the Coconut Research Institute of Sri Lanka - Part 1 (Review Papers and Guest Presentations), Peiris TSG, Ranasinghe CS (eds). Coconut Research Institute: Lunuwila; 111-148.

Peiris TSG, Thattil RO. 1998. The study of climate effects on the nut yield of coconut using parsimonious models. Journal of Experimental Agriculture 34: 189-206.

Peiris TSG, Thattil RO, Mahindapala R. 1995. An analysis of the effect of climate and weather on coconut (Cocos nucifera). Journal of Experimental Agriculture 31(4): 451-460.

Peiris TSG, Peiris TUS, Rajapaksha S. 2000. Prediction of annual national coconut production - a stochastic approach, Sri. Lanka Journal of Applied Statistics 1(1): 25-32.

Reynolds SG. 1979. A simple method for prediction of coconut yields. Philippine Journal of Coconut Studies 4(3): 41-44.

Zubair L. 2002. El-Niño-Southern Oscillation influences on Rice Production in Sri Lanka. International Journal of Climatology 22(2): 249-260.

Zubair L. 2003. Sensitivity of Kelani streamflow in Sri Lanka to ENSO. Hydrological Processes 17(12): 2439-2448.

Zubair L, Rao SC, Yamagata T. 2003. Modulation of Sri Lanka rainfall by the Indian Ocean Dipole. Geophysical Research Letters 10(2): $1063-1066$.

Zubair L, Ropelewski CF. 2006. The strengthening relations between ENSO and North-East Monsoon rainfall over Southern India and Sri Lanka. Journal of Climate 19(8): 1567-1575. 